\title{
Healthcare Translation and Entrepreneurial Training in and for Egypt-Case Study and Potential Impact Analysis
}

\author{
Michael Friebe \\ Institute of Medical Engineering, Otto-von-Guericke-University, Magdeburg, Germany \\ Email: www.inka-md.de, michael.friebe@ovgu.de
}

How to cite this paper: Friebe, M. (2017) Healthcare Translation and Entrepreneurial Training in and for Egypt-Case Study and Potential Impact Analysis. Open Journal of Business and Management, 5, 51-62. http://dx.doi.org/10.4236/ojbm.2017.51005

Received: November 18, 2016 Accepted: December 13, 2016

Published: December 16, 2016

Copyright $\odot 2017$ by author and Scientific Research Publishing Inc. This work is licensed under the Creative Commons Attribution International License (CC BY 4.0).

http://creativecommons.org/licenses/by/4.0/

\begin{abstract}
Demographic issue and dedicated local healthcare related problems (e.g. infections, sterility issues, healthcare politics, distribution of wealth, availability and quality of healthcare services) cause different disease patterns in Northern Africa, than in the developed world. Most medical technology equipment is developed in the first world however with the first world in mind. African nations need to develop medical technology products and services that solve the local problems, and are robust, easy to use, and inexpensive. Motivation for the development of dedicated products and services that address local healthcare problems starts during the university education. Students need to be stimulated to be open to healthcare innovation and entrepreneurship. This could eventually lead to products developed in Africa for Africa, which potentially also have a market in the cost conscious healthcare systems of the developed world. This paper presents a case study of a dedicated "healthcare innovation generation" lecture, adapted to Northern Africa, using interactive teaching tools combined with the Biodesign Process. The goal was to introduce new innovation teaching to identify current healthcare problems and subsequently work on creating innovative solutions with a multidisciplinary student team. Initially only $7 \%$ of the participants were serious about starting their own venture or working for a startupcompany. This number increased to $62 \%$. An increase in entrepreneurial spirit and activities stimulated by university-offered lecture programs could positively change healthcare delivery in Africa and provide products and services that could also be used in the cost-constrained developed world.
\end{abstract}

\section{Keywords}

Innovation Generation, Healthcare Translation, Multidisciplinary Innovation, Healthcare Entrepreneurship, Need Based Product Development, Biodesign, Reverse Innovation 


\section{Introduction}

Health care and health services delivery is a major concern in just about any country, in the developed world as well as in developing countries. "Globally, health care appears to be on a collision course with patient needs and economic reality" [1]. Healthcare is inefficient and economic outcomes evaluation shows relatively low productivity with a mismatch between what patients get and what care they should get [2] [3].

In most developed countries the main issues are the continuously increasing expenses with respect to the percentage increase of the gross domestic product (GDP). Part of that is the increasing life expectancy, and pharmaceutical and medical technology advances. The best care is now available, but at very high cost and with unequal access and erratic quality, which is both unsatisfactory and unsustainable [4].

It is also clear that new products and services need to be developed to address local healthcare delivery problems, deal with the ageing population and progress is required for a safe, patient-centred, efficient, and equitable restructuring of the healthcare system [5].

Life-style diseases (e.g. diabetes, strokes, malnutrition and obesity, ischemic heart diseases), also caused by a so-called "nutrition transition" from local and traditional to fast food, are a growing concern in the developed and the developing world and will require special efforts by politics, education, and the healthcare system [6] [7].

Using Northern Africa (Egypt) as an example, other and additional healthcare related problems can be observed. Pharmaceuticals and medical technology take a significantly higher share of total health care expenditure and therefore the access to advanced drugs and technologies is significantly lower.

For patients that do have the necessary financial resources almost all options for diagnosis and treatment are available, but for a majority of patients access to advanced healthcare is completely unavailable. It is also clear that recent gains in life expectancy have not been shared equally across socioeconomic groups [3].

Healthcare services in Egypt are currently delivered by a multitude of public service providers, the Health Insurance Organization (HIO), Non-Governmental Organisations (NGOs) and an expanding network of private practitioners and medical facilities.

Even though presence of multiple providers could imply competitive services, in reality, there is very limited or no performance assessment mechanisms or quality assurance [8] [9].

Repeated observations and systems analyses describe an overused, underfunded ailing health system. Additionally, in remote areas doctors and specialists are rarely available, and hospitals are lacking basic hygiene. Proper medication and nursing staff are scarce and not well trained, forcing patients to seek services and consumables elsewhere [10].

Private providers were emerging with the deterioration of the public health service that offered better and faster service, but at a high expense to many people in Egypt.

More and more families cannot afford paying for their healthcare anymore. This trend is reflecting uncompensated increase in prices of healthcare services and questions the efforts of the government to provide an affordable equal access healthcare system. 
The total Egypt healthcare expenditure per capita in 2013 was US\$ 539 or $5.2 \%$ of the GDP as compared to Germany, that spend US\$ 4813 and $11.3 \%$ of GDP on healthcare [11]. Germany and Egypt were used for comparison, as both have about the same population, representing developed and developing nations, and having different healthcare systems.

The main adult risk factors and mortality risks in Egypt are (values for the peer regional average after “-”) [8]:

- Male (22.5\%) and female (46.3\%) obesity-13\%/24.5\%

- Male tobacco use with $40 \%-33 \%$

- Male (27.1\%) and female (27\%) raised blood-pressure-30.7\%/29\%

- Male (7\%) and female (7.4\%) raised glucose levels-11\%/11.6\%

The risk factors do correlate well with the mortality rates indicating that with lifestyle education and changed nutrition plus a reduction of the high nicotine intake a significant increase in life expectancy (currently 73 compared to 82 for Germany) could be achieved.

The World Health Organisation (WHO) concluded that inter-professional education is necessary in creating a "collaborative practice-ready health workforce" capable of improving health outcomes [12].

While the need for multidisciplinary education is recognised, students are very rarely involved in discussions about future healthcare delivery and additionally collaboration among health care disciplines is not really happening [13] [14] [15].

Change could begin in a classroom/university setup by working on proper problem identification and teaching problem solving capabilities. This could stimulate collaboration and multidisciplinary competence that eventually will lead to better healthcare when these students will join the workforce or will bring their own ideas into the market as entrepreneurs [16].

However, in todays university based education system, commercialisation is neither taught properly, nor are the students motivated to go that route. Publication of research results is still considered the normal route, also in the education system of the developed world [17].

Developing countries can produce efficient and effective substitute health products and treatments that have a very high local value and research also shows that innovations from developing country can even transfer to developed countries [18].

In this context combined developed-developing country learning processes could potentially generate effective solutions for global health systems, as well as provide these reverse innovations from developing to developed countries [19] [20].

In the past, delivering affordable health care technologies into resource-poor regions of the world, was done with an almost exclusive focus on making things simpler, with lower specifications, and therefore cheaper, which had a very limited positive impact [21].

Local healthcare problems in consideration with local regulatory issues, proper training and education were rarely combined with these development efforts yet, which could also lead to local business and entrepreneurial opportunities [7] [21].

The focus of this case study is to show the influence and possibilities of the university 
based education system on addressing and changing local healthcare problems.

It also intends to answer the question on whether healthcare innovation generation training in interdisciplinary groups can stimulate new local healthcare related product and service developments and stimulate entrepreneurial activities along with it.

\section{Methods}

It is obvious that improving a healthcare system requires knowledge of that particular system, including the local problems and challenges.

Healthcare is setup, regulated, governed, controlled by a combination of multi-disciplinary groups and interests, but has one thing in common: all human parties involved are also participants and beneficiaries of the healthcare provided.

Creative people need to be exposed very early on to innovation processes and need to learn to work already as students in multi-disciplinary teams.

Based on substantial experience in teaching "Healthcare Innovation Generation" to graduate engineering students, a lecture series was developed for a private university in Egypt (misr university of science and technology-www.must.edu.eg) with following base concept and questions to be answered [22] [23] [24]:

- Lecture should be completed in 4 - 6 weeks

- Interdisciplinary healthcare teams have a higher and better innovation output and therefore students from Medicine, Biomedical Engineering, Pharmacy, Physical Therapy, Dentistry, and other faculties should be included.

- Participants need to understand what healthcare innovation actually means.

- During the lecture the student participants should evaluate and analyse the local healthcare system in Egypt and identify and prioritise areas of needed innovation.

- Introduce the students to innovation thinking, innovation generation, and related entrepreneurship with a special focus on Healthcare Products and Services.

- Mix the lectures with active team components and different innovation and leadership games.

- Show entrepreneurial opportunities and create some enthusiasm and empathy to solve problems in Northern Africa and for the discovery of unmet clinical needs.

A regular lecture with several hours per week over a period of a semester has proven not to be very efficient particularly during the normal teaching schedule. Better are intense block presentations with assignments after each lecture.

Three lecture blocks of 7 academic hours each in one week were followed by a 4 week break to work on the innovation project assignment, followed by 3 more lectures of 6 hours each (see Table 1).

First joint task was to evaluate how the Egyptian healthcare system is perceived by the students and which problems they see as the main challenges. Emphasis was on how the system is perceived not what the actual statistics say.

For that a normal SWOT (Strength/Weakness/Opportunity/Threats) analysis scheme was used-mainly as a means of showing the huge opportunities that come along with identified weaknesses-followed by a short joint workshop on the largest problems and challenges in Egypt with healthcare delivery (see Figure 1).

The perception of the students was actually well in line with the statistical facts [8]. 
Table 1. Lecture curriculum. The teaching was frequently complemented with innovation games and individual or group assignments.

\begin{tabular}{ccc} 
Content & $\underline{\text { Activities }} \quad \underline{\text { Assignments }}$ \\
\cline { 2 - 4 } &
\end{tabular}

7 academic hours per lecture day

1. Introduction to Healthcare Generation

2. Lecture Overview and Expectations

3. Technology Overview

WEEK 1 Day 1

4. Egypt Healthcare Analysis

5. Introduction to Design Thinking and Lean Entrepreneurship

1. Assignment Discussion "Unmet Clinical Need"

Day 2 2. Value Proposition Canvas

3. Business Model Canvas

4. Innovation Theory

Lecture

Break

1. Discuss first Group Assignment-group presentations

2. Introduction to Innovation problems and barriers

3. Lean process development

Day 3

4. Entrepreneurial issues

5. Conceptual Blockbusting

6. Types of Innovation Presentation
- Game: What is Innovation?

- SWOT Analysis of the Egypt Healthcare System

- Opportunities and Challenges

- Prototyping and Minimal Viable Product Exercise
- Business Model Canvas Exercises

Participant Introduction Sheet prior to Lecture. Individual Assignment: Come up with 5 "unmet clinical needs" in a selected medical speciality (e.g. cardiology, radiology, surgery, ...)

\section{Group Assignment:}

Complete Business Canvas on one of the selected ideas. Identify customer and create a Value Proposition Canvas for each customer.

Group Assignment: Refine the Business canvas. Identify 3 - 5 Key Opinion Leaders in each customer segment and conduct interviews. Record the changes and update the Canvas. Create a short presentation and Promotype (e.g. Cartoon) and an Elevator Pitch description.
1. Presentation and discussion of group assignments

2. Lecture on Intellectual Property and Patents

3. Introduction to Innovation Financing

4. Blue Ocean Strategy
Lean Startup exercise and game

- Exercise and game to Blue Ocean Strategy directly applied to the group assignment
1. Presentation and discussion of the group assignments

2. Introduction to Innovation Games

Day 2

3. Leadership Issues

4. Wrap-Up and Summary
- Teambuilding Exercise

- Two Innovation Games

- Canvas-game with "Constraints"

\section{Group Assignment:}

Prepare a

onepage statement

on Innovation Segments of the groups product/service idea. Compare your product/service with the competition. Prepare a Blue Ocean strategy

FINAL Group Assignment:

- 10 Page documentation of product/service

- Presentation file for 12 Minutes

- Marketing/Product pitch

Lecture Break

1. The "9" most important slides of the lecture

Day 3 2. Presentation of the FINAL Group Assignment

3. Discussion on viability and realization potential

Written Test (60 Minutes)

- Presentation of results 
Student Questionnaire ( $n=41$ )-INNOVATION HEALTHCARE EGYPT-misr University of Sciene and Technology

\begin{tabular}{|c|c|c|c|c|c|c|}
\hline DISEASE PROBLEMS & $\underline{\text { Number of Responses }}$ & & HEALTHCARE CHALLENGES & & $\underline{\text { Number of Responses }}$ & \\
\hline Disbetes & 30 & \# & Training of Medical Staff (12.9\%) & Lack of qualified Doctors (specialists) & 12 & $@$ \\
\hline $\begin{array}{l}\text { Coronary Artery Calcification } \\
\text { and other Cardiac Problems }\end{array}$ & 12 & \# & & $\begin{array}{l}\text { Poor nurse training... society status } \\
\text { of nursing is too low }\end{array}$ & 4 & @ \\
\hline Blood Pressure & 7 & \# & Empathy and Motivation (9.7\%) & $\begin{array}{l}\text { too much orientation towards revenue } \\
\text { generation (medical doctors }+ \text { hospitals) }\end{array}$ & 4 & $@$ \\
\hline Renal Failure & 6 & $\#$ & & $\begin{array}{l}\text { Missing empathy of doctors } \\
\text { and hospital staff }\end{array}$ & 8 & \\
\hline Hepatitis C & 25 & \# & Hospital Related Issues (28.2\%) & Missing Sterility in hospital care-infections & 11 & @ \\
\hline $\begin{array}{l}\text { Liver Cirrhosis } \\
\text { (see also Hepatitis) }\end{array}$ & 9 & $\#$ & & Overfilled public hospitals & 9 & $@$ \\
\hline Parasitic/Bacterial Infections & 7 & \# & & Poorly equipped hospitals & 5 & \\
\hline Breast Cancer & 5 & & & Medication errors in hospitals & 5 & \\
\hline Bladder Cancer & 4 & & & $\begin{array}{l}\text { Limited treatment guidelines/QA guidelines/ } \\
\text { missing communication platforms }\end{array}$ & 5 & $@$ \\
\hline Substance abuse & 5 & & General HC Problems (29\%) & Missing availability of services in rural areas & 6 & $@$ \\
\hline $\begin{array}{l}\text { Pulmonary Lung Disease } \\
\text { (smoking or air pollution related) }\end{array}$ & 3 & \# & & $\begin{array}{l}\text { Emergency medicine as a major problem } \\
\text { (traffic issues) }\end{array}$ & 8 & @ \\
\hline \multirow[t]{2}{*}{ Other } & 10 & \# & & Late disgnosis and no prevention & 3 & @ \\
\hline & & & & $\begin{array}{l}\text { Patient training/education-lifestyle changes } \\
\text {-Food and Activity }\end{array}$ & 10 & @ \\
\hline @ & $\begin{array}{l}\text { Government Influence/ } \\
\text { Changes needed to } \\
\text { improve/resolve }\end{array}$ & & Environment (7.3\%) & Environmental related diseases (Water/Air) & 9 & @ \\
\hline \# & $\begin{array}{l}\text { Lifestyle Eduction and } \\
\text { improvements in Sterility } \\
\text { and Environment could } \\
\text { significantly reduce }\end{array}$ & & Others $(20.2 \%)$ & Other challenges & 25 & $@$ \\
\hline
\end{tabular}

Figure 1. Identified disease problems (left part) and healthcare challenges (right part). Many of the challenges cause the diseases and most of them can only be addressed with the strong support of the regulatory offices/government input. A majority of the diseases that were identified are related to lifestyle changes and could be lowered with proper patient/population education.

Diabetes, heart problems, liver problems, and cancer were recognised as the main killers. Figure 1 shows these perceived disease problems on the left and the healthcare challenges on the right that were clustered into categories.

The major healthcare challenges were seen in general healthcare sterility issues, missing therapy and procedure guidelines, and medication errors. Together they were summarised as "hospital related issues" (28.2\%), because they happen during diagnosis and treatment at the hospital.

Lack of medical staff training (12.9\%, due to missing specialisation for doctors and poor overall training for nurses), low motivation and missing patient empathy of all healthcare workers $(9.7 \%)$ were the other identified challenges.

Particularly the last point was very shocking and surprising coming from 'almost' graduates about to enter the workforce.

The data evaluation was not statistically relevant, because of a relatively low number of participants $(n=41)$, and because of the interdisciplinary student population. Also the participants had only limited exposure to the real healthcare delivery. But all students are also all participants in the healthcare system and have been involved as patients, supporter and observer of family health issues, and as future employees. With that the provided information has a significant value.

Other challenges identified were seen in the inequality of healthcare access in rural areas, the lack of emergency services (traffic related), and environmental issues like water and air pollution. 
A majority of these challenges require the input, guidance, and regulation of political structures to be solved. These structures are slow, provide unclear responsibility structures, and are inefficient. Possibly the reason for the high frustration level among the students.

The SWOT also mentioned as "opportunity" the large number of trained doctors that could be employed as medical specialists with extra training and to fill rural medical staffing needs. This also requires government input.

It was also noted that there is generally enough money available for the healthcare system, but that this is very unequally distributed and-again-with government input could be optimised. The low amount (5.2\% of GDP [8]) that is spend provides further opportunities for improvement.

Main goal of the lecture was to teach the participants to find isolated innovative solutions-based on the general problems-that can potentially be implemented relatively easy through entrepreneurial activities.

This Egypt Healthcare SWOT analysis and the identification of the main problems were done in the first lecture block.

Based on these identified challenges and needs the students were then asked to individually provide ideas for products or services that were discussed in lecture block 2 and evaluated using the value proposition canvas [23].

Figure 2 shows an example of such a canvas.

Subsequently the student voted on the five favourite topics (which were later reduced to only four), that were then assigned to the teams for the following more in depth assignments.

The identified and prioritised topics were:

- Portable Water Treatment Device

- Single Use Surgical Tools

- Portable Dialysis Unit-dedicated Northern Africa Version

- Electronic Medical ID

- Virtual Healthcare Hotline

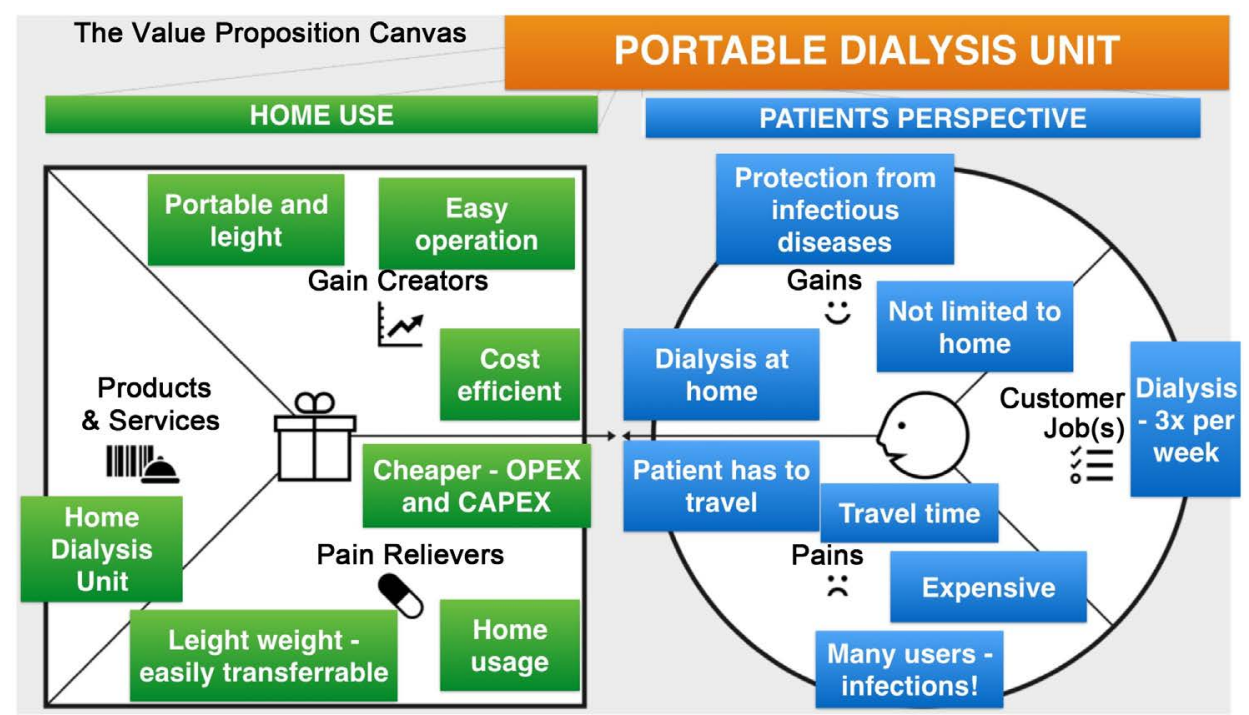

Figure 2. Example of a "value proposition canvas"-a key instrument in innovation generation. 
The initial group assignment after block 3 and to be completed in the break period, was to provide a business model and value proposition canvas with a particular focus on understanding the customer (Who is the healthcare customer actually?) and to analyse and understand their needs (What is the job that the customer has to complete? What are the current problems-Pains? What would improve the situation and health care delivery-Gains?).

For every customer an individual Value Proposition Canvas (VPC) needed to be completed [22] [23].

E.g. a "portable dialysis user" has many potential customers/stakeholders: nephrologist, pharmacist, hospital administrator, patient, healthcare provider, ...And everyone has individual Pains and Gains. Only with a understanding of all these stakeholders meaningful and valuable innovation is possible.

Figure 2 shows the VPC from the customer "patient" perspective.

The task was not to ensure a correct and diligent initial work, but to have a starting point and to subsequently discuss among the team members of "Who" the customer actually is, what the "Job" of the customer is, and what possible "Pains" in the current job can be identified in combination with possible "Gains".

This was then compared with the anticipated performance of the initial product/service.

For the innovation process this is done multiple times and is constantly improved by implementing and changing what has been learned by talking to the customers and from the insights that are obtained while working on the problem solution.

The assignment in the 4 week break after block 3 and block 4 was used by the student groups to

- gather information

- talk to customers

- understand the customers problems and concerns

- possibly change the customer and start all over again

Goal was to prepare a first draft of an innovation concept that would eventually consist of a very short, but easily understandable description of the offered product/service and its advantages and value propositions.

That paper was to be combined with a

- "value proposition canvas" (initial version and subsequent changes),

- "business model canvas" (initial version and subsequent changes),

- list of key opinion leaders of the productl service research,

- SWOT analysis and BLUE OCEAN strategy (Kim),

- idea for a first prototype,

- and a conclusive statement on the next steps and the things learned.

It was particularly difficult to get the students to come up with a short and precise description of their idea. But this is key to getting proper, accurate, and valuable responses from your customer. It is difficult to provide a valuable opinion, if the customer does not understand the value propositions and the business concept of the healthcare innovation proposal.

Some teams used small cartoon movies/sketches or came up with a worded pictogram to describe their ideas. Much easier to understand then to provide a comprehen- 
sive description.

An example of such a cartoon sketch is shown in Figure 3.

\section{Results and Conclusion}

The lecture series was voluntary and held during the semester break in Egypt. 21 students (roughly 1/4 each from Medicine, Biomedical Engineering, Pharmacy, and Physical Therapy and an equal share of male and female students), attended all 6 block lectures of 7 academic hours each. The attendance was throughout the duration high. Initially 41 students started in block 1, which reduced to 21 by lecture 3 . All of these 21 continued through lecture 6 and completed all the individual and team assignments.

The final documentation and the subsequent customer and product research were of the same high quality that is observed with similar groups and lectures in Europe (Friebe, 2015).

The enthusiasm of the students increased over time as they got more and more involved in "their" topic and product idea. Just like in similar lectures in Europe they found out that their initial idea needed a lot of technical and business fine-tuning with respect to delivery specifications. In all completed innovation projects the initially
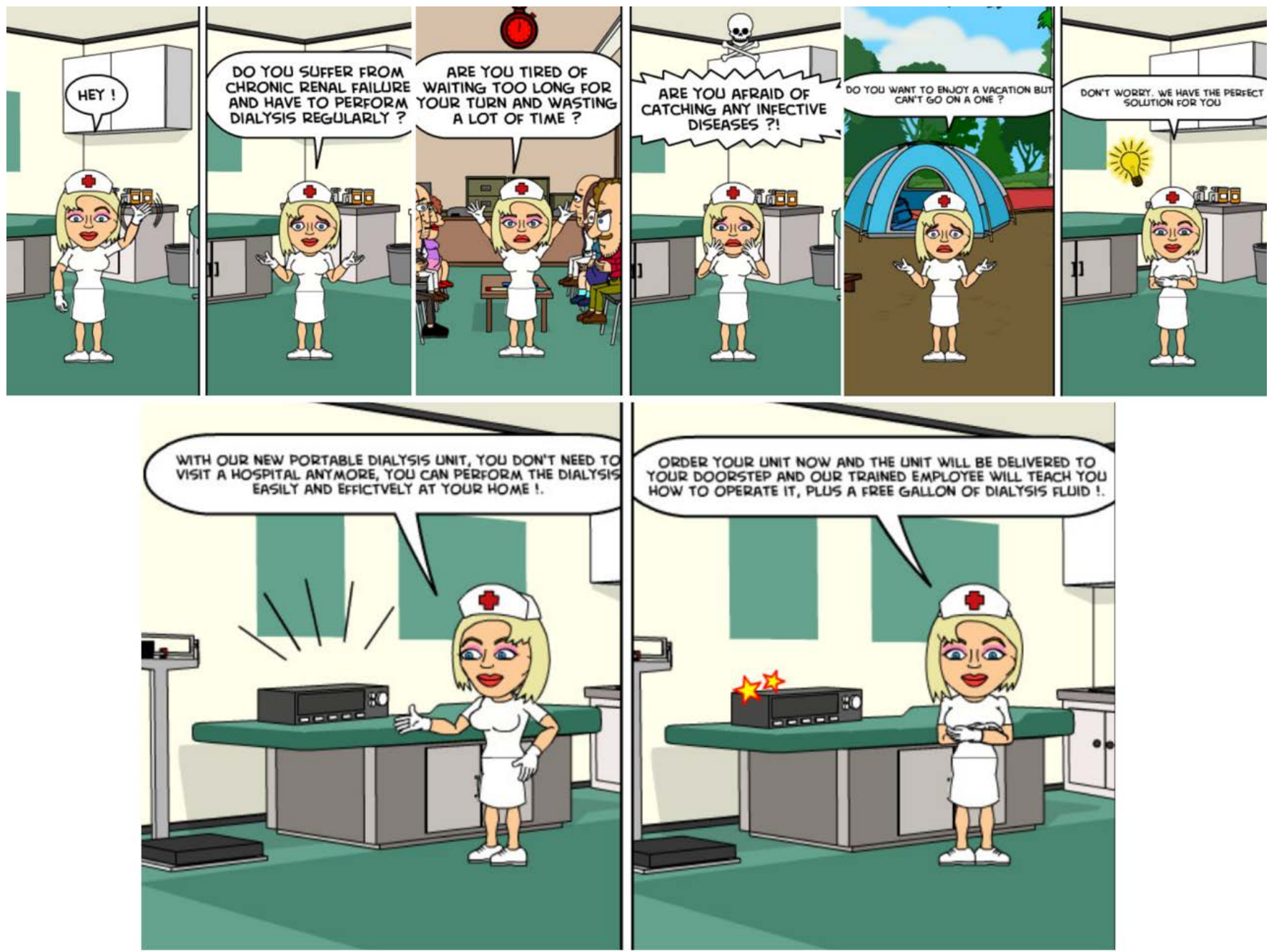

Figure 3. A cartoon made by one of the student groups explaining some of the value propositions of a portable dialysis unit. 
identified main customer changed, a very important change when defining and working on an innovation project!

It could also be observed that the seriousness and personal engagement of the student groups increased. That is not typically seen in European groups, where the students very often take a similar lecture initially only because it is fun or because it is mandatory.

Students learned to analyse and evaluate healthcare related problems and to find innovative local product and service solutions and were able to come up with a rough implementation strategy.

It also provided the students with the understanding that they are potentially able to solve unmet clinical needs by addressing and changing local healthcare problems.

Based on the students enthusiasm and the quality of the innovation projects it can be positively argued that a dedicated healthcare innovation generation training can stimulate new local healthcare related product and service developments and with that potentially stimulate entrepreneurial activities.

Only a very small number of attendees (as per an initial questionnaire before the beginning of the lecture series) were initially interested in any entrepreneurial activities.

All showed a high level of frustration with the healthcare system and their future roles as medical doctors (oversupply, but lack of specialisation), pharmacists (medical doctor for the poor, without official recognition), biomedical engineers (no proper job perspective), or Physical Therapists (role/function not appreciated and properly reimbursed).

Their main initial motivation to attend was looking for opportunities outside the established and expected roles after graduation.

All students that finished concluded that they learned things that changed their current viewpoint and their attitude and made them believe they can actually change things with their own actions despite large problems and political and administrative hurdles in Egypt.

When asked on whether they would now consider a career as an entrepreneur as a potential future option, $36 \%$ clearly said Yes and another $26 \%$ said they would prefer to participate as a team member of a start-up company rather than to work for established companies or organisations.

While this is not a solid and statistically relevant scientific result, it shows that dedicated Innovation Generation training for a multidisciplinary group of students in combination with entrepreneurial ideas is one of several things that need to be present to produce creative, and forward looking innovators that will positively influence and subsequently restructure a healthcare system with many problems, but also many opportunities.

The educational system (and with that the government) is well advised to offer in the future entrepreneurial courses in a multidisciplinary setup dedicated to stimulate healthcare innovation and address local product and service innovation processes.

The presented lecture format is only a starting point and an introduction to further educational offerings in healthcare innovation and entrepreneurship that need to follow, but highlight the possible effects of early innovation training on entrepreneurial 
stimulation.

Misr university in Egypt has decided to continue the lecture in the coming semesters and to make it part of the teaching curriculum of several faculties. This will be combined with further university offerings on commercialisation of the identified innovation projects.

The educational system needs to lead the way with offerings and own activities to identify and analyse local healthcare problems and provide the technical and educational means to come up with local product and service solutions. This could also eventually lead to needed political changes affecting healthcare and associated delivery issues.

\section{Acknowledgements}

Great thanks to Prof. M. El-Azzazi, president of Misr University of Science and Technology (www.must.edu.eg) for being on open supporter of a new interactive and multidisciplinary way of identifying healthcare innovation needs. ... and of course thanks a lot to all the students that went through the lecture over a 6 week period, invested a lot of their free time, and showed an amazing amount of enthusiasm. And lastly I would like to show gratitude to the Otto-von-Guericke-University, my employer, for allowing me to spend the time in Egypt away from my normal role teaching and actually implementing HEALTHCARE INNOVATIONS.

The lecture and research was supported by the German ministry of education and research-BMBF-under grant 03IPT7100X and by a guest professor grant of the German academic exchange service DAAD (www.daad.de).

\section{References}

[1] Creativity, P.R. (2014) Innovation and Entrepreneurship: A New Prescription for Health Care. Innovation and Entrepreneurship in Health, 1, 1-3.

[2] Cutler, D. (2010) Where Are the Health Care Entrepreneurs? The Failure of Organizational Innovation in Health Care. Innovation Policy and the Economy, 11, 1-28. https://doi.org/10.1086/655816

[3] Yong, P., Saunders, R. and Olsen, L., Eds. (2010) The Healthcare Imperative: Lowering Costs and Improving Outcomes: Workshop Series Summary. Institute of Medicine (US) Roundtable on Evidence-Based Medicine, Washington DC. http://www.ncbi.nlm.nih.gov/pubmed/21595114

[4] Herzlinger, R. (2012) Benchmark for Confronting the Challenges for Innovation in Healthcare with a Modern Curriculum. http://www.hbs.edu/healthcare/Documents/benchmarks for_confronting challenges for_i nnovation in health care with a modern curriculum.pdf

[5] Institute of Medicine (2001) Crossing the Quality Chasm: A New Health System for the 21st Century. The National Academies Press, Washington DC.

[6] Howard, J. (2014) Medical Devices and the Middle East: Market, Regulation, and Reimbursement in Gulf Cooperation Council States. Medical Devices. Evidence and Research, 7, 385-395. https://doi.org/10.2147/MDER.S73079

[7] Boumedjout, H. (2012) Cardiovascular Diseases on the Increase in Arab States. (Published Online) https://doi.org/10.1038/nmiddleeast.2012.36

[8] WHO Egypt (2015) WHO Statistical Profile. 
http://www.who.int/gho/countries/egy.pdf?ua=1

[9] WHO (2016) Country Cooperation Strategy for Egypt. http://applications.emro.who.int/docs/CCS Egypt 2010 EN 14481.pdf

[10] Abdelkader, A. (2016) Egypt Healthcare System Past and Future. http://pathology.mcw.edu/wp-content/uploads/Egypt Healthcare System Past and Futur e.pdf

[11] WHO Germany (2015) WHO Statistical Profile. http://who.int/countries/deu/en/

[12] Fren, J., Chen, L., Bhutta, Z.A., et al. (2010) Health Professionals for a New Century: Transforming Education to Strengthen Health Systems in an Interdependent World. Lancet, 376, 1923-1958. https://doi.org/10.1016/S0140-6736(10)61854-5

[13] World Health Organization (2006) World Health Report 2006-Working Together for Health. Geneva. http://apps.who.int/iris/bitstream/10665/43432/1/9241563176 eng.pdf

[14] Grumbach, K. and Bodenheimer, T. (2004) Can Health Care Teams Improve Primary Care Practice? JAMA, 291, 1246-1251. https://doi.org/10.1001/jama.291.10.1246

[15] Kumarasamy, M.A. and Sanfilippo, F.P. (2015) Breaking down Silos: Engaging Students to Help Fix the US Health Care System. Journal of Multidisciplinary Healthcare, 8, 101-108. https://doi.org/10.2147/JMDH.S79384

[16] Mitchell, P.H., Wynia, M., Golden, R., McNellis, B., Okun, S., Webb, C.E., Rohrbach, V. and von Kohorn, I. (2012) Core Principles \& Values of Effective Team-Based Health Care. Discussion Paper, Institute of Medicine, Washington DC. https://www.nationalahec.org/pdfs/VSRT-Team-Based-Care-Principles-Values.pdf

[17] Spertus, J. (2015) Leveraging Entrepreneurship as a Means to Improve the Translation of Outcomes Research to Healthcare Improvement. Circulation: Cardiovascular Quality and Outcomes, 8, 2-3. http://dx.doi.org/10.1161/CIRCOUTCOMES.114.001641 https://doi.org/10.1161/CIRCOUTCOMES.114.001641

[18] Immelt, J., Govindarajan, V. and Trimble, C. (2009) How GE Is Disrupting Itself. Harvard Business Review, 87, 56-65. https://hbr.org/2009/10/how-ge-is-disrupting-itself

[19] Syed, S.B., Dadwal, V., Rutter, P., Storr, J., Hightower, J.D., Gooden, R., Carlet, J., Nejad, S.B., Kelley, E.T., Donaldson, L. and Pittet, D. (2012) Developed-Developing Country Partnerships: Benefits to Developed Countries? Globalization and Health, 8, 17. https://doi.org/10.1186/1744-8603-8-17

[20] Crisp, N. (2010) Turning the World Upside down: The Search for Global Health in the 21st Century. CRC Press, London. https://doi.org/10.1201/b13481

[21] Glifford, G. (2016) The Use of Sustainable and Scalable Health Care Technologies in Developing Countries. Innovation and Entrepreneurship in Health, 3, 35-46.

[22] Friebe, M. and Traub, J. (2015) Image Guided Surgery Innovation with Graduate Students-A New Lecture Format. Current Directions in Biomedical Engineering, 1, 475-479. https://doi.org/10.1515/cdbme-2015-0114

[23] Osterwalder, A., Pigneur, Y., Bernarda, G., Smith, A. and Papadakos, T. (2014) Value Proposition Canvas. Wiley, Hoboken.

[24] Zenios, S., Makower, J., Yock, P., Brinton, T., et al. (2015) Biodesign-The Process of Innovating Medical Technologies. Cambridge University Press, Cambridge. 
Submit or recommend next manuscript to SCIRP and we will provide best service for you:

Accepting pre-submission inquiries through Email, Facebook, LinkedIn, Twitter, etc. A wide selection of journals (inclusive of 9 subjects, more than 200 journals)

Providing 24-hour high-quality service

User-friendly online submission system

Fair and swift peer-review system

Efficient typesetting and proofreading procedure

Display of the result of downloads and visits, as well as the number of cited articles Maximum dissemination of your research work

Submit your manuscript at: http://papersubmission.scirp.org/

Or contact ojbm@scirp.org 